\title{
А.Н. Авраменко
}

\section{ЧИСЛЕННОЕ МОДЕЛИРОВАНИЕ ПРОЦЕССА ОБРАБОТКИ ВОДОТОПЛИВНОЙ ЭМУЛЬСИИ В БОРТОВОМ ГИДРОДИНАМИЧЕСКОМ КАВИТАТОРЕ}

\begin{abstract}
В работе представлены результаты численного моделирования процесса обработки водотопливной эмульсии с использованием гидродинамического кавитатора. Задача решается в трехмерной нестационарной постановке. При моделировании прочесса гидродинамической кавитации рассматривается двухфазный поток - жидкая и паровая фазы. Использование гидродинамических кавитаторов на борту автомобиля позволит поддерживать стабильность смесевых топлив и повысит эффективность их использования.
\end{abstract}

\section{Введение}

Для улучшения экологических показателей ДВС традиционно используют различные методы: воздействие на рабочий процесс (внутренние) и очистка отработавших газов (внешние). Одним из эффективных методов является предварительная подготовка топлива. Применительно к дизельным двигателям, к примеру, снижение содержания серы в дизельном топливе благоприятно сказывается на снижении массового выброса твердых частиц. Одним из эффективных способов снижения содержания серы в дизельном топливе является гидродинамическая кавитация. Исследованием процесса кавитации занимаются многие зарубежные исследователи [1-3]. В последнее время зарубежные исследователи все больше уделяют внимание использованию в ДВС водотопливных эмульсий, как для бензиновых так и для дизельных двигателей [4-6].

Организация рабочего цикла дизеля на водотопливной эмульсии позволяет снизить максимальную температуру цикла, и тем самым, с незначительными потерями мощности эффективно воздействовать на снижение уровня оксидов азота $\mathrm{NO}_{\mathrm{x}}$ в отработавших газах.

\section{Анализ публикаций}

Ключевой проблемой для обеспечения эффективной работы дизеля на водотопливной эмульсии, наряду с необходимостью обеспечить коррозионную стойкость элементов топливной аппаратуры, является поддержание стабильности эмульсии на борту транспортного средства. Одним из способов стабилизации водотопливных эмульсий является добавка различных присадок к топливу [6-9].

Использование гидродинамической кавитации для гомогенизации топлива широко применяется в промышленности [7]. Этот процесс характеризуется высокой эффективностью воздействия при минимальных энергетических затратах. Так, к примеру, смесь бензина с головной фракцией - бензоэтанол, после смешивания в гидродинамическом кавитаторе остается стабильной в течении 2-3 месяцев в зависимости от влияющих факторов $[7,8]$.
Применительно к транспортным средствам, реализация гидродинамической кавитации для поддержания стабильности смесевых топлив на борту автомобиля требует разработки малогабаритных гидродинамических кавитаторов, выбора наиболее рациональных режимов обработки смесевого топлива с учетом энергозатрат, эффективности воздействия и ресурса проточной части гидродинамического кавитатора.

Таким образом, можно сделать вывод о том, что работы, направленные на разработку бортовых систем поддержания стабильности смесевых топлив, являются актуальными и требуют дальнейших исследований.

\section{Цель и постановка задачи}

Цель работы - исследование процессов теплои массообмена в малогабаритном гидродинамическом кавитаторе с использованием численных методов.

В работе ставились такие задачи:

- провести литературный обзор по современным способам поддержания стабильности смесевых топлив;

- разработать конструкцию малогабаритного гидродинамического кавитатора для поддержания стабильности водотопливной эмульсии на борту автомобиля;

- исследовать процесс кавитации водотопливной эмульсии в малогабаритном гидродинамическом кавитаторе с использованием численных методов; - дать рекомендации по рациональным режимам работы гидродинамического кавитатора для обработки водотопливной эмульсии.

Основные этапы и результаты исследования

Объект исследования - процессы тепло- и массообмена в малогабаритном гидродинамическом кавитаторе.

С учетом существующих рекомендаций и экспериментальных исследований была разработана оригинальная конструкция бортового гидродина- 
мического кавитатора, на которую был получен патент Украины [10].

Схема гидродинамического кавитатора представлена на рис. 1.

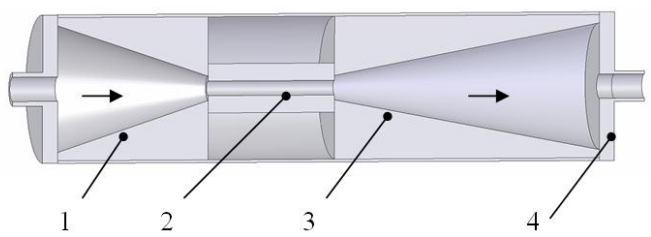

Рис. 1. Схема гидродинамического кавитатора: 1 -конфузор; 2 - соединительньй канал;3 - диффузор; 4 - корпус

Для проведения численных исследований процессов тепло - и массообмена в малогабаритном гидродинамическом кавитаторе была синтезирована расчетная область и расчетная сетка, описывающие проточную часть гидродинамического кавитатора. Внешний вид расчетной области представлен на рис. 2, а расчетной сетки - на рис. 3 .

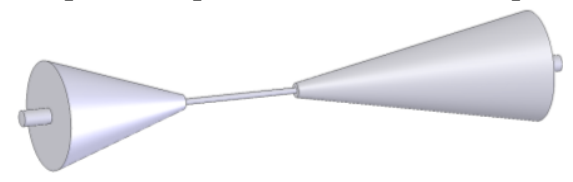

Рис. 2. Внешний вид расчетной области

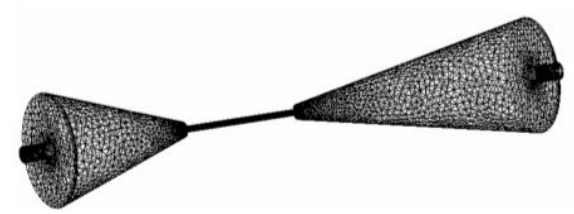

Рис. 3. Расчетная сетка (150043 расчетных ячеек)

Применительно к условиям штатной топливной системы транспортного средства с дизельным двигателем, малогабаритный кавитатор имеет длину 180 мм, диаметр конфузора и диффузора 40 мм, диаметр соединительного - канала 2 мм. Материал проточной части - нержавеющая сталь.

Задача решалась в нестационарной трехмерной постановке, в декартовых координатах. Для описания турбулентных течений водотопливной эмульсии в проточной части кавитатора использовались k-е модель турбулентности.

Для описания процесса гидродинамической кавитации использовалась модель многофазных течений. С учетом ограничений используемой модели (модель не позволяет описывать процесс фазового перехода двух компонент одновременно дизельного топлива и воды) в работе рассматривается топливная композиция с усредненными теп- лофизическими параметрами (95\% дизельного топлива и 5\% воды). База данных программного комплекса была дополнена свойствами нового рабочего тела - водотопливной эмульсии. Для описания процесса течения двухфазного потока (пар и жидкость) в работе использовалась модель смеси (Mixture model).

В расчете учитывалась шероховатость стенок проточной части гидродинамического кавитатора и теплообмен между стенками и рабочим телом (водотопливной эмульсией).

Результаты расчетного исследования представлены на рис. 4 и 5.
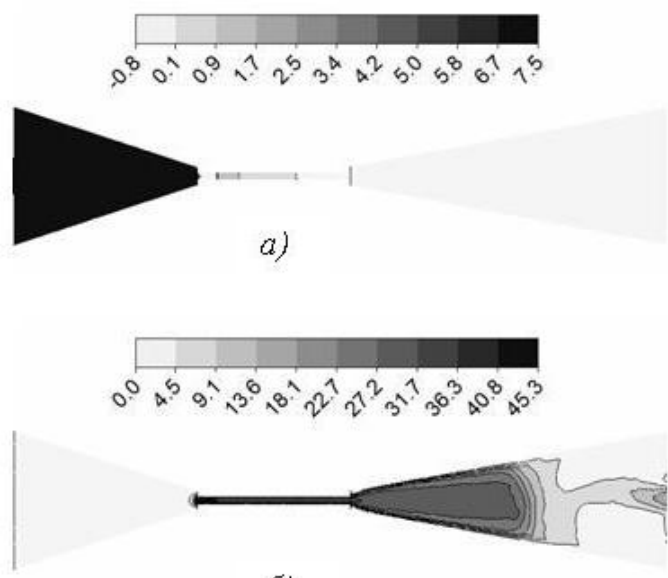

6)
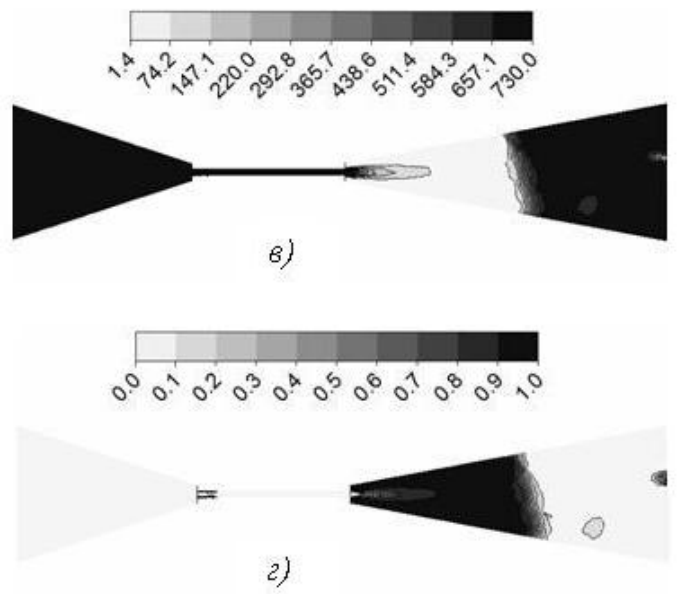

Рис. 4. Результаты расчетного исследования:

a - распределение давления, атм; б- скорости, м/с;

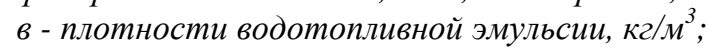

2 - объемной доли паровой фазы в проточной части гидродинамического кавитатора

Распределение давления водотопливной эмульсии в меридиональном сечении проточной части гидродинамического кавитатора представлен на рис. 4.а. В конфузоре давление потока водотопливной эмульсии достигает 0,75 МПа. В соедини- 
тельном канале между конфузором и диффузором поток набирает скорость, и давление в нем снижается до уровня, ниже атмосферного - 0,01 МПа. На входе в диффузор скорость потока остается достаточно высокой и, соответственно, давление сохраняется ниже атмосферного - 0,08 МПа, что ниже давления насыщенных паров водотопливной эмульсии.

Распределение полной скорости по различным участкам потока топлива в меридиональном сечении проточной части гидродинамического кавитатора представлено на рис. 4 б). На входе в конфузор полная скорость потока топлива достигает 4 м/с. При движении через соединительный канал между конфузором и диффузором поток набирает скорость до 45,3 м/с, при этом уже в соединительном канале наблюдается зарождение кавитационных каверн из-за резкого падения давления.

Распределение плотности рабочего тела (смеси жидкости и паров водотопливной эмульсии) в меридиональном сечении проточной части гидродинамического кавитатора представлено на рис. 4 в). Наибольшее снижение плотности отмечается на участках с пониженным давлением - в области зарождения кавитационных каверн.

Распределения объемной доли паровой фазы водотопливной эмульсии в меридиональном сечении проточной части гидродинамического кавитатора представлен на рис. 4 г).

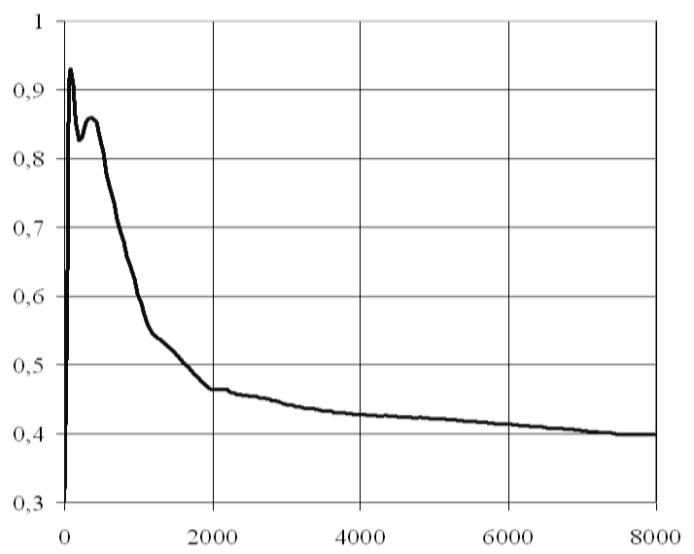

Рис. 5. Изменение сходимости объемной доли паровой фазы водотопливной эмульсии в проточной части гидродинамического кавитатора в зависимости от количества итераџий

Осредненное по объему изменение сходимости объемной доли паровой фазы водотопливной эмульсии в проточной части гидродинамического кавитатора в процессе расчета представлено на рис. 5. 
tational Physics, Vol. 186, pp. 361-396, 2003. doi: 10.1016/s0021-9991(03)00011-1. 3. Brennen, C.E. Fundamentals of Multiphase Flows / Cambridge University Press, 2005. doi: 10.1017/cbo9780511807169. 4. Александров А.А. Альтернативные топлива для двигателей внутреннего сгорания [Текст]: монография / А.А. Александров,И.А. Архаров, В.В. Багров и др. - М.: ООО НИЦ «Инженер», 2012. - 790 c. 5. Fuel Economy of 2013 Flex-Fuel (E85) Vehicles [Електронний ресурс] /U.S. Department of Energy. - 2012. - Режим доступа: http://www.fueleconomy.gov/feg/byfuel/ FFV2013.html. 6. ADAPTER E85 [Електронний ресурс] / GREEN-BUTTON ECOTECHNICS. - 2011. - Режим docmyna: http://kulvit.narod.ru 7. Производство высококачественного товарного смесевого бензина из дешевых компонентов. Гомогенизация бензинов. [Електронний ресурс]: - 2007. - Режим доступа: http://ukrbudmash.kazprom.net/p2696-ustanovka-smesevyhbenzinov.html 8. Топливный кавитатор - экономия топлива. [Електронний ресурс] - 2014. - Режим доступа: http://www.afuelsystems.com/ru/cavitator.html 9. Иванов A. H. Гидродинамика развитых кавитачионных течений [Текст]: монография, Л., Судостроение 1980 - 237 с. 10. Пат. 97284, Украина, МПК F02M 27/08 (2006.01), F02M 27/04 (2006.01) Топливный кавитатор [Текст] / Левтеров, А. М., Авраменко, А. Н., Мараховский, В. П., Бганцев, B. Н. - Заявитель и патентодержатель "Институт проблем машиностроения им. А.Н. Подгорного” НАН Украины. - № и 2014 09044. - Заяв. 11.08.2014. Опубл. 10.03.2015. Бюл. № 5

\section{Bibliography (transliterated):}

1. Ventikos, Y., Tzabiras G. (2000), A numerical method for the simulation of steady and unsteady cavitating flows, Computers and Fluid 29, P. 63-88,. doi: 10.1016/s0045-7930(98)00061-9. 2. Abgrall, R., Saurel R. (2003), Discrete Equations for Physical and Numerical Compressible Multiphase Mixtures Journal of Computational Physics, Vol. 186, pp. 361-396,. doi: 10.1016/s00219991(03)00011-1. 3. Brennen, C.E. (2005), Fundamentals of Multiphase Flows, Cambridge University Press. doi: 10.1017/cbo9780511807169. 4. Aleksandrov, A.A., Arkharov, I.A., Bagrov V.V. (2012), Alternative fuel for internal combustion engines: monograph [Al'ternativnye topliva dlya dvigatelei vnutrennego sgoraniya: monografiya], OOO NITs «Inzhener», Moscow, 790 p. 5. Fuel Economy of 2013 Flex-Fuel (E85) Vehicles. (2012),U.S. Department of Energy. Rezhim dostupa: http://www.fueleconomy.gov/feg/byfuel/FFV2013.html. 6. ADAPTER E85. (2011), GREEN-BUTTON ECOTECHNICS Rezhim dostupa: http://kulvit.narod.ru. 7. Proizvodstvo vysokokachestvennogo tovarnogo smesevogo benzina iz deshevykh komponentov. Gomogenizatsiya benzinov. (2007) Rezhim dostupa: http://ukrbudmash.kazprom.net/p2696-ustanovka-smesevyh-

benzinov.html 8. Toplivnyi kavitator - ekonomiya topliva. (2014) Rezhim dostupa: http://www.afuelsystems.com/ru/cavitator.html 9. Ivanov A. $N$ (1980), Hydrodynamics advanced cavitations flows: monograph [Gidrodinamika razvitykh kavitatsionnykh techenii: monografiya], Sudostroenie, Leningrad, 237 p. 10. Pat. 97284, Ukraina, MPK F02M 27/08 (2006.01), F02M 27/04 (2006.01) Fuel cavitator [Toplivnyi kavitator] / Levterov, A. M. Avramenko, A. N., Marakhovskii, V. P., Bgantsev, V. N. - Zayavitel' i patentoderzhatel' "Institut problem mashinostroeniya im. A.N. Podgornogo" NAN Ukrainy. - № u 2014 09044. - Zayav. 11.08.2014. Opubl. 10.03.2015. Byul. № 5 .

Авраменко Андрей Николаевич - канд. техн. наук, старш. научн. сотр. ИМПаш им. А.Н. Подгорного НАН Украины, Харьков, Украина, e-mail: an0100@yandex.ru.

\title{
ЧИСЕЛЬНЕ МОДЕЛЮВАННЯ ПРОЦЕСУ ОБРОБКИ ВОДОПАЛИВНОЇ ЕМУЛЬСІЇ У БОРТОВОМУ ГІДРОДИНАМІЧНОМУ КАВІТАТОРІ
}

\author{
А.М. Авраменко
}

В роботі представлені результати чисельного моделювання процесу обробки водопаливної емульсії з використанням гідродинамічного кавітатору. Задача вирішується в тривимірній нестаціонарній постановці. При моделюванні процесу гідродинамічної кавітації розглядається двофазний потік - рідинна та парова фази. Використання гідродинамічних кавітаторів на борту автомобіля дозволить підтримувати стабільність сумішевих палив та підвищити ефективність їх використання.

\section{NUMERICAL MODELLING OF PROCESS OF INFLUENCE WATER-FUEL EMULSION IN ONBOARD HYDRODYNAMICAL CAVITATOR}

\section{A.N. Avramenko}

In article results of numerical modelling of processing water-fuel emulsion are submitted on the basis of diesel fuel and water with use hydrodynamic cavitation. The problem is solved in three-dimensional non-stationary production. At modelling process hydrodynamic cavitation, the biphasic stream - liquid and steam phases is considered. Use hydrodynamic activator onboard the automobile will allow to support stability fuels mix and will raise efficiency of their use. 
УДК 621.

\title{
А.П. Марченко, Омар А. Хамза, Али А. Хамза
}

\section{ОЦЕНКА ИНВЕСТИЦИОННОЙ ПРИВЛЕКАТЕЛЬНОСТИ ЭНЕРГОСБЕРЕГАЮЩИХ ТЕХНОЛОГИЙ НА ОСНОВЕ ТЕПЛОВЫХ ДВИГАТЕЛЕЙ ПРИМЕНИТЕЛЬНО К НЕФТЕПЕРЕРАБАТЫВАЮЩЕМУ ЗАВОДУ}

\begin{abstract}
Выполнена оченка инвестиционной привлекательности энергосберегающих технологий на основе тепловых двигателей применительно к нефтеперерабатывающему заводу. Рассматривались два проекта. Проект $A$ включал газотурбинный двигатель (ГТД) UGT-3000, а проект Б - ГТД TV3 - 117 и поршневой двигатель САТ G3516. Результаты технико-экономической оценки на основании чистой приведенной стоимости NPV показали, что экономически более привлекателен проект Б.
\end{abstract}

\section{Введение и постановка проблемы}

В процессе переработки нефти большое количество попутных нефтяных газов (ПНГ) сжигается в факелах и загрязняет окружающую среду. Эта проблема постоянно обсуждается на международных конференциях, проводимых под эгидой ООН и Всемирного банка. Ирак входит в пятерку стран, с наибольшим количеством сжигаемых в атмосфере углеводородов (рис. 1). В апреле 2015 г. Генеральным секретарем ООН Пан Ги Муном и председателем Всемирного банка Джим Йонг Кимом была запущена инициатива "Zero Routine Flaring by 2030” по прекращению сжигания углеводородов в факелах до 2030 года. Эту инициативу поддержали правительства и нефтедобывающие компании по всему миру.

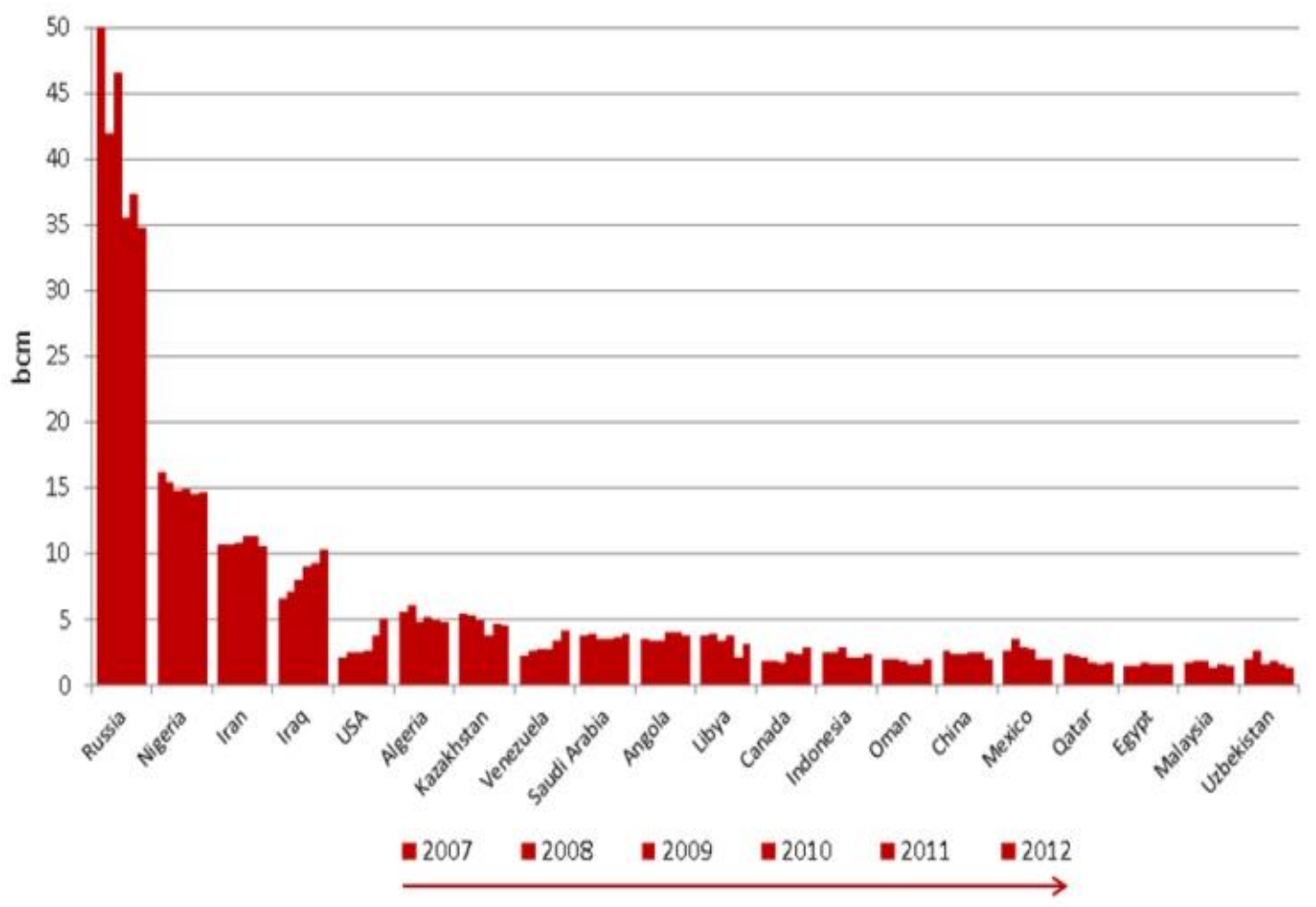

Рис. 1. Страны с наибольшим уровнем сжигания углеводородов в факелах [1]

Одним из наиболее рациональных путей решения представленной проблемы, на наш взгляд, является утилизация попутного газа в тепловых энергетических установках с получением на выходе электрической энергии, что очень актуально при отсутствии близкого доступа предприятий к электрическим сетям.
Утилизация теплоты попутного нефтяного газа позволяет не только снизить уровень загрязнения окружающей среды, но и дать дополнительный экономический эффект.

Максимально возможная прибыль от эксплуатации энергосберегающего оборудования прямо связана с чистой приведенной стоимостью. Чистая приведенная стоимость рассчитывается $[2,3]$ с ис- 
пользованием прогнозируемых денежных потоков, связанных с планируемыми инвестициями в проект энергосбережения на предприятии, по следующей формуле

$$
N P V=\sum_{i=1}^{N} \frac{N C F_{i}}{(1+r)^{i}}-\operatorname{In} v,
$$

где $N C F_{i}$ - чистый денежный поток для $i$-го периода; Inv - начальные инвестиции; $r$ - ставка дисконтирования (стоимость капитала, привлеченного для инвестиционного проекта).

При положительном значении $N P V$ считается, что данное вложение капитала является эффективным. Однако, использование метода NPV невозможно без анализа технических характеристик энергосберегающего оборудования, что вызывает необходимость проведения такого анализа.

Анализ технических характеристик энергосберегающего оборудования

Существует несколько путей утилизации попутного нефтяного газа. Углеводороды, составляющие ПНГ, можно использовать в химическом производстве, в производстве теплоты и электрической энергии. Из этих вариантов наибольшую привлекательность на нефтеперерабатывающем заводе представляет генерация электроэнергии. В настоящее время наибольшее распространение в качестве генераторов электроэнергии получили дизельгенераторы и турбогенераторы. Однако, термодинамические характеристики тепловых двигателей значительно зависят от температуры окружающей среды $[4,5]$. Параметры окружающей среды в большой мере влияют на технико-экономические характеристики ГТД [4-7]. Сравнение альтернативных технических решений возможно на основании сопоставимости их начальных технических характеристик. Применительно к условиям эксплуатации на нефтеперерабатывающем заводе в качестве оборудования рекуперации бросовой теплоты можно рассматривать следующие варианты газотурбинных двигателей UGT-3000 и TV3-117. Данные по влиянию температуры окружающей среды на мощность газотурбинных двигателей UGT-3000 [6] и TV3-117 [7] представлены на рис. 2.

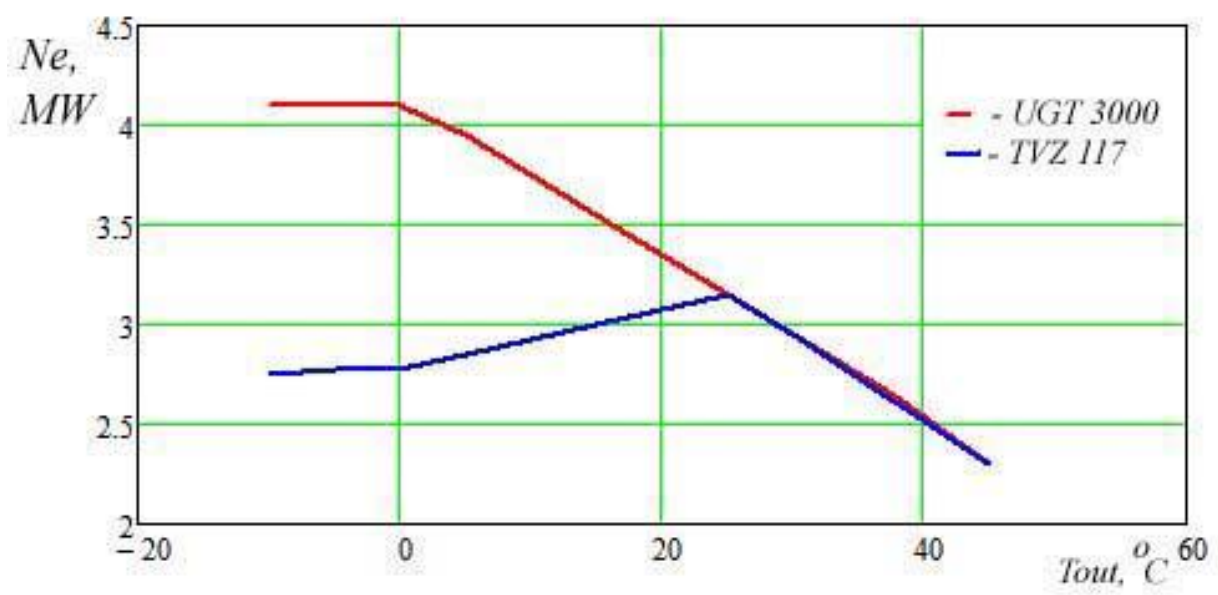

Рис. 2. Зависимость мощңности газотурбинных двигателей UGT-3000 и TV3-117 от температурь наружного воздуха $\left(T_{\text {out }}\right)$

Более $2 / 3$ времени года на территории Ирака преобладает температура воздуха окружающей среды более $20^{\circ} \mathrm{C}$. Это обуславливает целесообразность использования в технико-экономических расчетах технические характеристики оборудования при температурах наружного воздуха более $20{ }^{\mathrm{O}} \mathrm{C}$.

На основании приведенных выше данных газотурбинных двигателей UGT-3000 и ГТД TV3-117 нами рассмотрены два проекта энергосбережения на нефтеперерабатывающем заводе. Проект А включает энергоустановку на базе ГТД UGT-3000 (рис. 3), проект Б - на базе ГТД TV3-117 и, допол- нительно, поршневого двигателя САТ G3516 (рис. 4) [8].

В качестве положительных сторон проекта можно принять экономические эффекты от: производства электричества для потребностей нефтеперерабатывающего завода, которое сохраняет денежные средства на плату за электроэнергию внешним поставщикам; производство добавочного электричества, которое может продаваться населению и экономического эффекта по защите окружающей среды из-за снижения эмиссии вредных продуктов в атмосферу. 


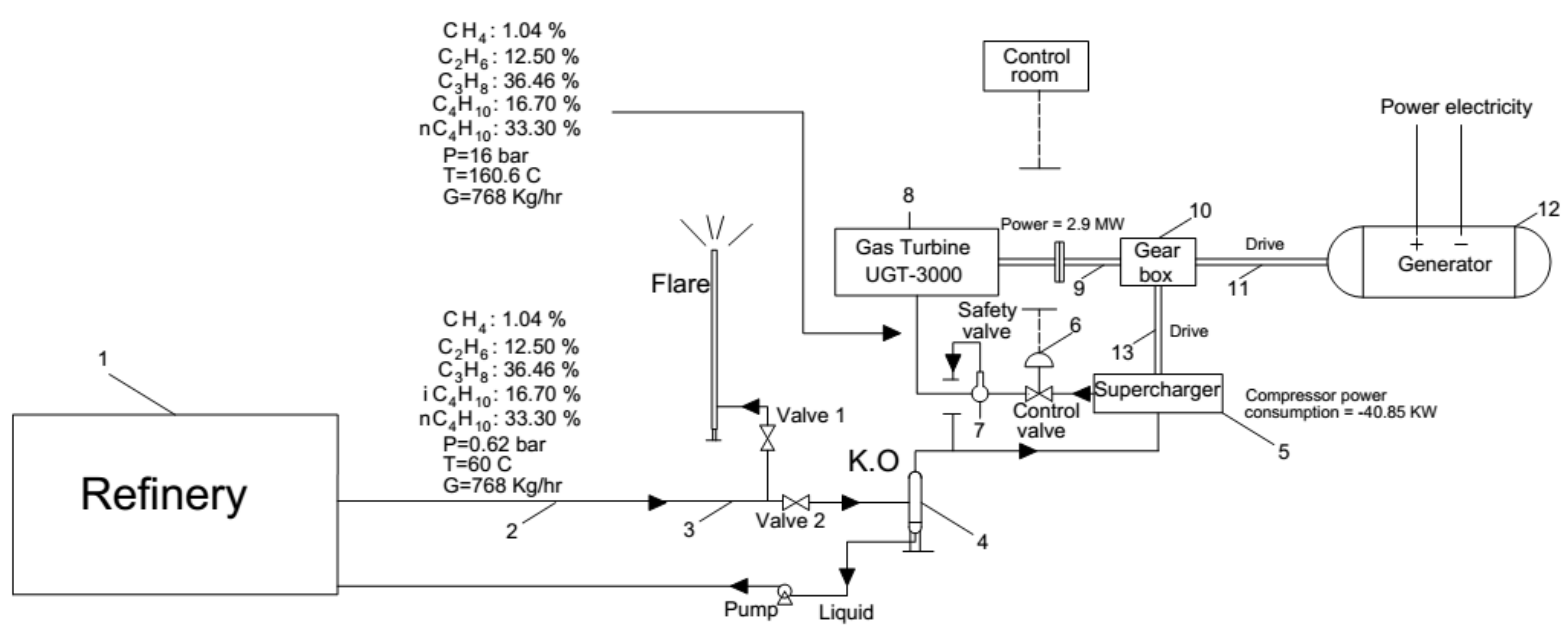

Рис. 3. Схема проекта A

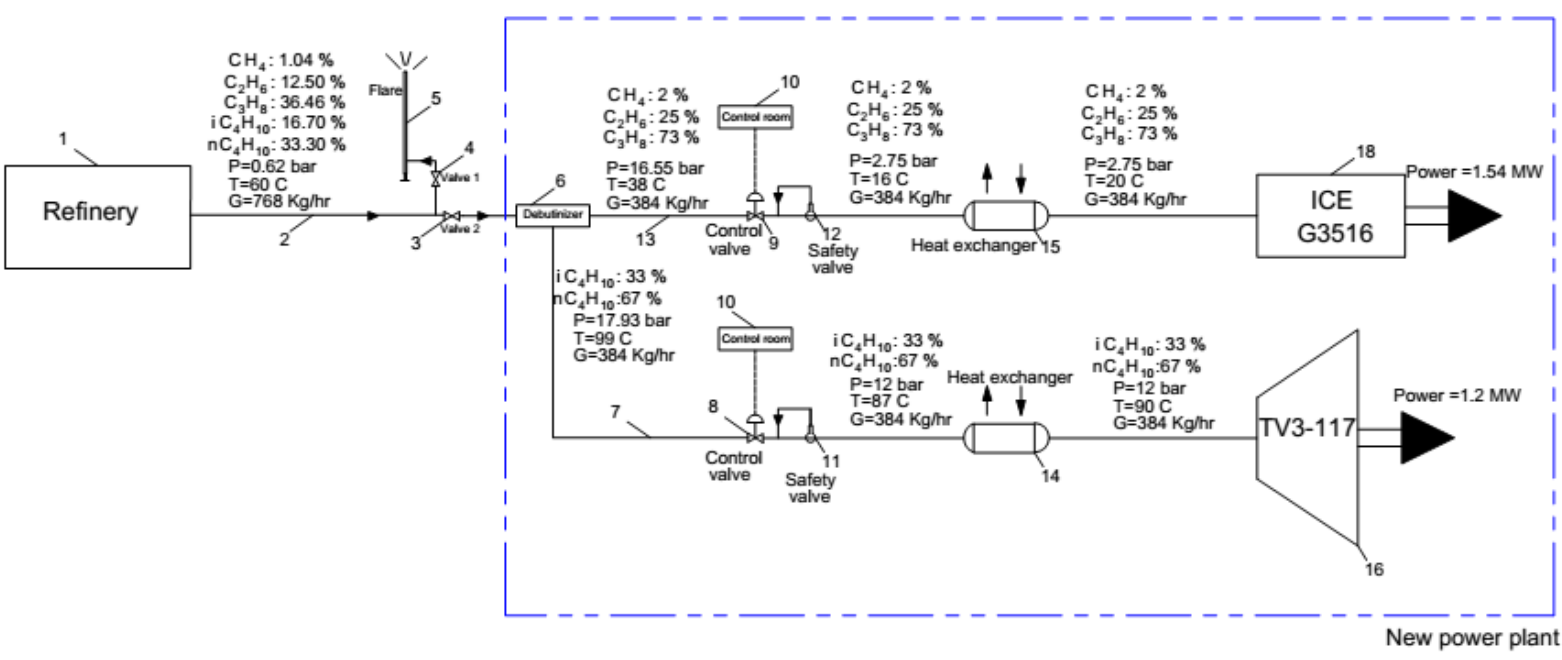

Рис. 4. Схема проекта Б

$\mathrm{B}$ соответствии с $[2,3]$ для проведения оценки инвестиционной привлекательности энергосберегающего оборудования на основе газотурбинного двигателя UGT-3000 (Проект А) и ГТД TV3-117 с поршневым двигателем СAT G3516 (Проект Б) рассматривались следующие составляющие финансовых затрат в проекте:

- первоначальные инвестиции или стоимость единицы;
- экономия на оплате за электроэнергию;

- продажа электроэнергии;

- поддержание расходов.

В расчетах экономической эффективности принят срок службы энергосберегающего оборудования 20 лет.

Результаты оценки инвестиционной привлекательности для обоих проектов представлены в табл. 1.

Таблица 1. Результаты расчетов инвестиционной привлекательности

\begin{tabular}{|l|c|c|}
\hline \multicolumn{1}{|c|}{ Показатели } & Проект А & Проект Б \\
\hline NPV (Чистая приведенная стоимость) & $\$ 1964434,69$ & $\$ 2843009,55$ \\
\hline DPB (Дисконтированный срок окупаемости) & 6 лет и 1 месяц & 3 лет и 8 месяцев \\
\hline IRR (Внутренняя норма доходности) & $21,00 \%$ & $32,11 \%$ \\
\hline MIRR (Модифицированная IRR) & $12,24 \%$ & $14,51 \%$ \\
\hline PI (индекс рентабельности) & 2,017 & 3,013 \\
\hline
\end{tabular}


Таблица 1 показывает, что проект Б лучше проекта А и возврат вложенных инвестиций произойдет значительно быстрее (3 года и 8 месяцев против 6 лет и 1 месяца в проекте А).

Анализ чувствительности к температуре в двух проектах электростанций, показал, что этот фактор не является существенным для проекта Б, поскольку снижение NPV очень мало даже при самой высокой возможной температуре $\left(+45{ }^{\circ} \mathrm{C}\right.$ весь год) [9]. Таким образом, анализ чувствительности показал наиболее влияющим фактором цену электроэнергии на рентабельности проекта. График NPV проектов, в зависимости от стоимости ставок капитала определяется как чистая приведенная стоимость профиля проекта [2]. Для рассматриваемых проектов этот параметр приведен на рис. 5.

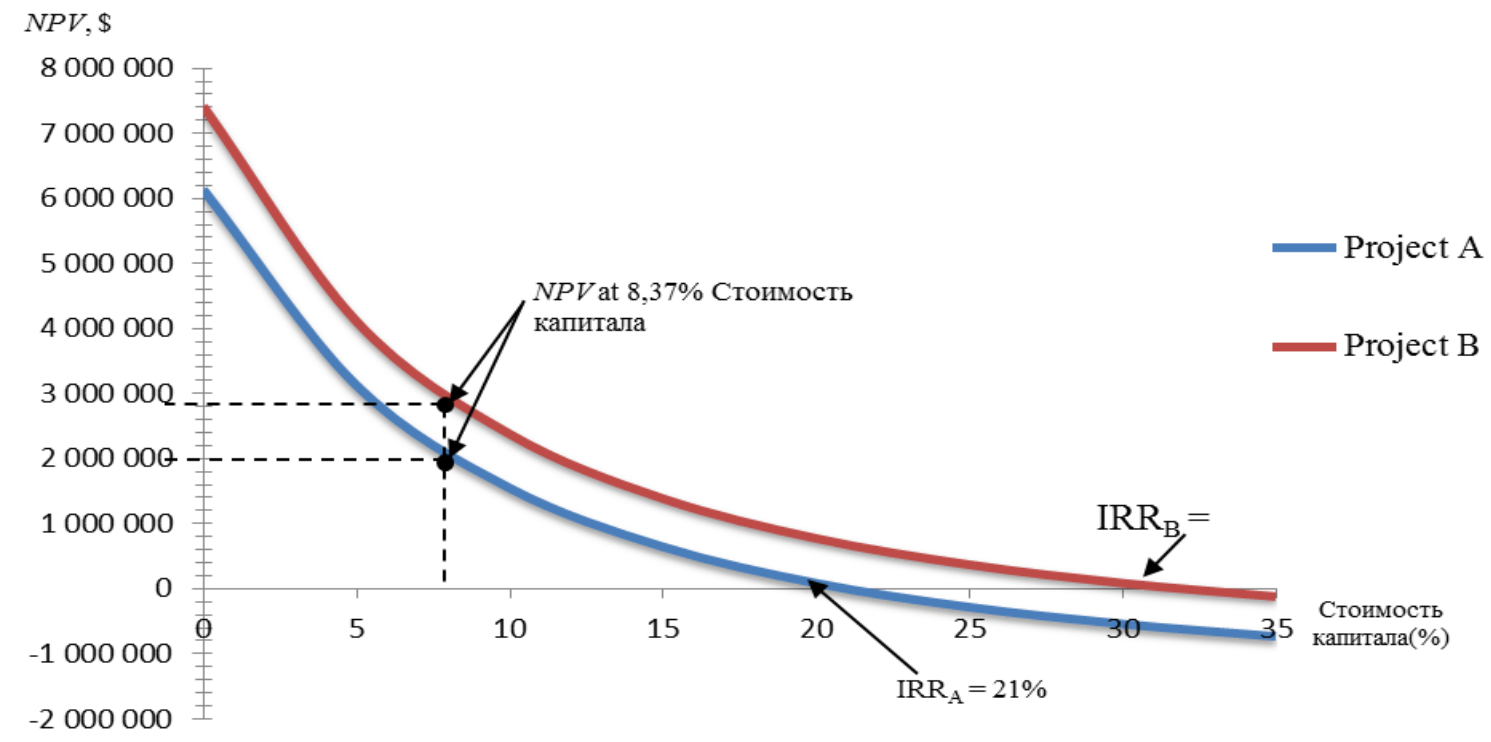

Рис. 5. Чистая приведенная стоимость для проектов А и Б

\section{Заключение}

В работе были рассмотрены два проекта энергосбережения на нефтеперерабатывающем заводе. Проект А (энергоустановка на базе ГТД UGT-3000) и проект Б (на базе ГТД TV3-117 и поршневого двигателя CAT G3516). Проект Б оказался лучшим решением с точки зрения всех влияющих параметров. Его дисконтированный срок окупаемости составляет 3 года и 8 месяцев, внутренняя норма доходности составляет $32,11 \%$, a MIRR равна $14,51 \%$. Кроме того, каждый доллар, вложенный в проекте Б дает \$ 3,013 прибыли.

Анализ рисков проекта Б привел к выводу, что снижение цен на электроэнергию оказывает существенное негативное влияние на экономические показатели проекта.

Анализ чувствительности к температуре окружающей среды показал, что этот показатель не является существенным, так как даже при самой высокой возможной температуре $\left(+45^{\circ} \mathrm{C}\right.$ весь год) ЧПС уменьшается только на $6 \%(\$ 173644,8)$.

\section{Список литературы:}

1. Инициатива по сокращению глобального сжигания газа на факелах [Электронный ресурс]: Группа органи- заций Всемирного банка - электронные данные. - Режим docmyna: http://www.worldbank.org/en/programs/zeroroutine-flaring-by-2030/brief/initiative-to-reduce-global-gasflaring (viewed on May 22, 2015). - Title from the screen. 2. Евтюхин Н.А., Результаты проведенного энергоаудита установок первичной переработки нефти НовоУфимского НПЗ, получаюших масляные фракции [Текст]/ Н.А. Евтюхин, Е.В.Бурдыгина // Региональные проблемы энергосбережения и пути их решения: Тез. докл. VI Всерос. конф. - Нижний Новгород: НГТУ, 2002. - C. 20. 3. E.F. Brigham, J.F. Houston Fundamentals of Financial Management (13th edition) // South-Western Cengage Learning, 2013, 816 р. 4. Виленский П.Л. Оиенка эффективности инвестиционных проектов. Теория и практика. 2-е изд., перераб. и доп [Текст]/ П.Л. Виленский, В.Н. Лившии, С.А. Смоляк.- М.: Дело, 2002. - 888 с. 5. Carcedo S.F. Influencia de la temperatura del aire en loa parámetros, de loa motores ZIL-130 [Text] / S.F. Carcedo Transporte y Viae de Comunicación, Habana, 1983, Vol. 3, No.3, p. 350-361. 6. Газотурбинный двигатель НК-1618CT. [Электронный ресурс] / Режим доступа: www.kmpo.ru/dl.php?id=223. 7. Двигун TB3-117BMAСБМ-1В-03 [Электронный ресурс]/- Режим доступа: http://uos.ua/produktsiya/aviakosmicheskaya-tehnika/90dvigatel-tv3-117vma-sbm-1v-03/. 8. Современные газотурбинные агрегаты. Том 1. Агрегаты производства предприятий Украины и России. [Электронный ресурс]/Режим достуnа: bib.convdocs.org/v11080/? download=19. Погода в Ираке. [Электронный ресурс]/- Режим достуna: http://weather14days.com/Asia/Iraq/ 


\section{Bibliography (transliterated):}

1. Initiative to reduce global gas flaring [electronic resource]: The World Bank Group [Initsiativa po sokrascheniyu globalnogo szhiganiya gaza na fakelah] - the electronic data. - Access mode: http://www.worldbank.org/en/programs/zero-routine-flaring-by2030/brief/initiative-to-reduce-global-gas-flaring (viewed on May 22, 2015). - Title from the screen. 2. Yevtyukhin N.A., Burdygina E.V. (2002) "The results of the energy audit units of primary oil refining Novo-Ufa Refinery receiving oil fractions" Regional problems of energy conservation and ways to solve them ["Rezultatyi provedennogo energoaudita ustanovok pervichnoy pererabotki nefti Novo-Ufimskogo NPZ, poluchayuschih maslyanyie fraktsii" Regionalnyie problemyi energosberezheniya i puti ih resheniya] Abstracts VI All-Russian Conference - Nizhny Novgorod: Novosibirsk State Technical University, P. 20. 3. Brigham E.F., Houston J.F. (2013) "Fundamentals of Financial Management (13th edition)" SouthWestern Cengage Learning, , 816 p. 4. PL Vilenskii, VN Livshits, SA
Smolyak (2002) Evaluating the effectiveness of investment projects. Theory and practice. 2nd edition [Otsenka effektivnosti investitsionnyih proektov. Teoriya i praktika.] Moscow, "Delo" publishing, 888 p. 5. Carcedo S.F. (1983) "Influencia de la temperatura del aire en loa parámetros, de loa motores ZIL-130" Transporte y Viae de Comunicación, Habana, Vol. 3, No. 3, pp. 350-361. 6. A gas turbine engine NK-16-18ST. [Electronic resource] / Access: www.kmpo.ru/dl.php?id=223 7. Engine TV3-117VMA-SBM1V-03 [Electronic resource] Access: http://uos.ua/produktsiya/aviakosmicheskaya-tehnika/90-dvigateltv3-117vma-sbm-1v-03/. 8. Modern gas turbine Assemblies. Volume 1. Aggregates production enterprises of Ukraine and Russia. [Electronic resource] / - Access: bib.convdocs.org/v11080/?download=1 9. Weather in Iraq. [Electronic resource] / - Access. http://weather14days.com/Asia/Iraq/

Поступила в редакиию 07.06.2016

Марченко Андрей Петрович - доктор техн. наук, проф., проректор по научной работе Национального технического университета «Харьковский политехнический институт», Харьков, Украина, e-mail: marchenko@kpi.kharkov.ua

Хамза Омар А. - аспирант кафедры двигателей внутреннего сгорания Национального технического университета «Харьковский политехнический институт», Харьков, Украина, e-mail: eng_omaradel@yahoo.com

Хамза Али А. - аспирант кафедры двигателей внутреннего сгорания Национального технического университета «Харьковский политехнический институт», Харьков, Украина, e-mail: alihitman2000@yahoo.com

\section{ОЦІНКА ІНВЕСТИЦЙНОЇ ПРИВАБЛИВОСТІ ЕНЕРГОЗБЕРІГАЮЧИХ ТЕХНОЛОГІЙ НА ОСНОВІ ТЕПЛОВИХ ДВИГУНІВ СТОСОВНО НАФТОПЕРЕРОБНОГО ЗАВОДУ}

\section{А.П. Марченко, Омар А. Хамза, Алі А. Хамза}

Виконано оцінку інвестиційної привабливості енергозберігаючих технологій на основі теплових двигунів стосовно нафтопереробного заводу. Розглядалися два проекти. Проект А включав газотурбінний двигун (ГTД) UGT-3000, а проект Б - ВМД TV3 - 117 і поршневий двигун CAT G3516. Результати техніко-економічної оцінки на підставі чистої приведеної вартості NPV показали, що економічно більш привабливий проект Б.

\section{EVALUATION OF INVESTMENT ATTRACTIVENESS ENERGY SAVING TECHNOLOGY BASED ON HEAT ENGINES RELATION TO OIL REFINERIES}

\section{A.P. Marchenko, Omar A. Hamza, Ali A. Hamza}

The estimation of investment appeal of energy saving technologies based on heat engines relation to the refinery. We considered two projects. The project included A gas turbine engine (GTE) UGT-3000, and the project B - GTD TV3 - 117 and piston engine CAT G3516. The results of technical and economic evaluation on the basis of net present value NPV showed that economically more attractive is project $\mathrm{B}$. 